\title{
RENAL SODIUM AND WATER CONSERVATION IN ACUTE PARAPLEGIA
}

\author{
By D. P. McCarthy and C. B. Wilmot \\ The National Medical Rehabilitation Centre, Dun Laoghaire, Co. Dublin, and \\ The Metabolic Unit, St. Vincent's Hospital, Dublin
}

\section{INTRODUCTION}

THE appearance of abnormal polyuria in quadriplegic patients has previously been documented by Brown et al. (1959) and by Sitprija et al. (1966). The pattern of results obtained by Sitprija et al. suggests that the polyuria was a simple consequence of excessive oral water intake due to psychogenic polydypsia. We have further investigated a group of seven such patients with reference to renal ability to conserve both water and sodium during restricted oral intake. Our interest in the syndrome has stemmed from the known effects of intrarenal instillation of nor-epinephrine and acetyl-choline on sodium excretion (Barger et al., 1959) and from the recent studies of Gill et al. (1964) on the effects of adrenergic blockade on renal excretion of a sodium load. It appeared possible that any defect in renal sodium conservation resulting from interruption of renal innervation might be detected in this way, particularly if studies were carried out in the first week or two subsequent to spinal injury.

\section{METHODS}

Abnormal renal sodium conservation has been defined as persistence of urinary sodium loss in excess of intake beyond five days following commencement of a low sodium diet (Crabbe, 1958). Patients were started on a low sodium intake ( $17 \mathrm{mEq}$./day) as soon as possible following admission to the Paraplegic Unit. Admission was commonly within 24 hours and at latest within II days of injury. Seven subjects with paraplegia were studied. All had sustained injury to the cervical spinal cord between $\mathrm{C}_{4}$ and $\mathrm{C}_{7}$. No patient with significant soft tissueor other bony injuries was included.

The Protocol of study was as follows:

On Admission. Physical examination noting level of lesion, nature of trauma, blood pressure, evidence of oedema. Low sodium diet begun. Start first 24-hour urine collection. Record fluid intake.

Zero Time. Blood taken for electrolytes, osmolality, urea, $\mathrm{Hb}$ and haematocrit in fasting subjects.

At 24 hours. First 24-hour urine volume recorded and $\mathrm{Na}, \mathrm{K}$, creatinine concentrations measured.

7 p.m. Day 2 to II a.m. Day 3. Sixteen-hour fluid deprivation with separate collection of final two-hour urine specimen for maximum urinary osmolality.

Days 2, 3, 4, 5, 6 and 7. Twenty-four-hour urine collections. Blood daily for electrolytes and osmolality. Continue low Na diet. B.P. six-hourly.

Day 8 (or 9): Restore to free diet.

Collection of urine and blood samples was carried out daily under the supervision of one of us (D. McC.). All biochemical estimations were carried out in 
the laboratory of the Metabolic Department. An overall summary of clinical details and results obtained during the sodium restriction study is given in Table I. Seven studies of external sodium balance during sodium restriction were carried out in six patients (patient P. D. had two studies with an interval of four weeks). A careful record was kept of the daily serum sodium and B.P. levels during the time of dietary sodium restriction in order to detect possible early signs of body sodium depletion. In no case were such signs detected.

\section{BIOCHEMICAL METHODS}

Balance Technique. The dietary sodium intake was estimated by the dietician and in all cases was less than $20 \mathrm{mEq}$. per day. Urine was collected in 24 -hour volumes and stored without preservative. Since the faecal sodium content on a

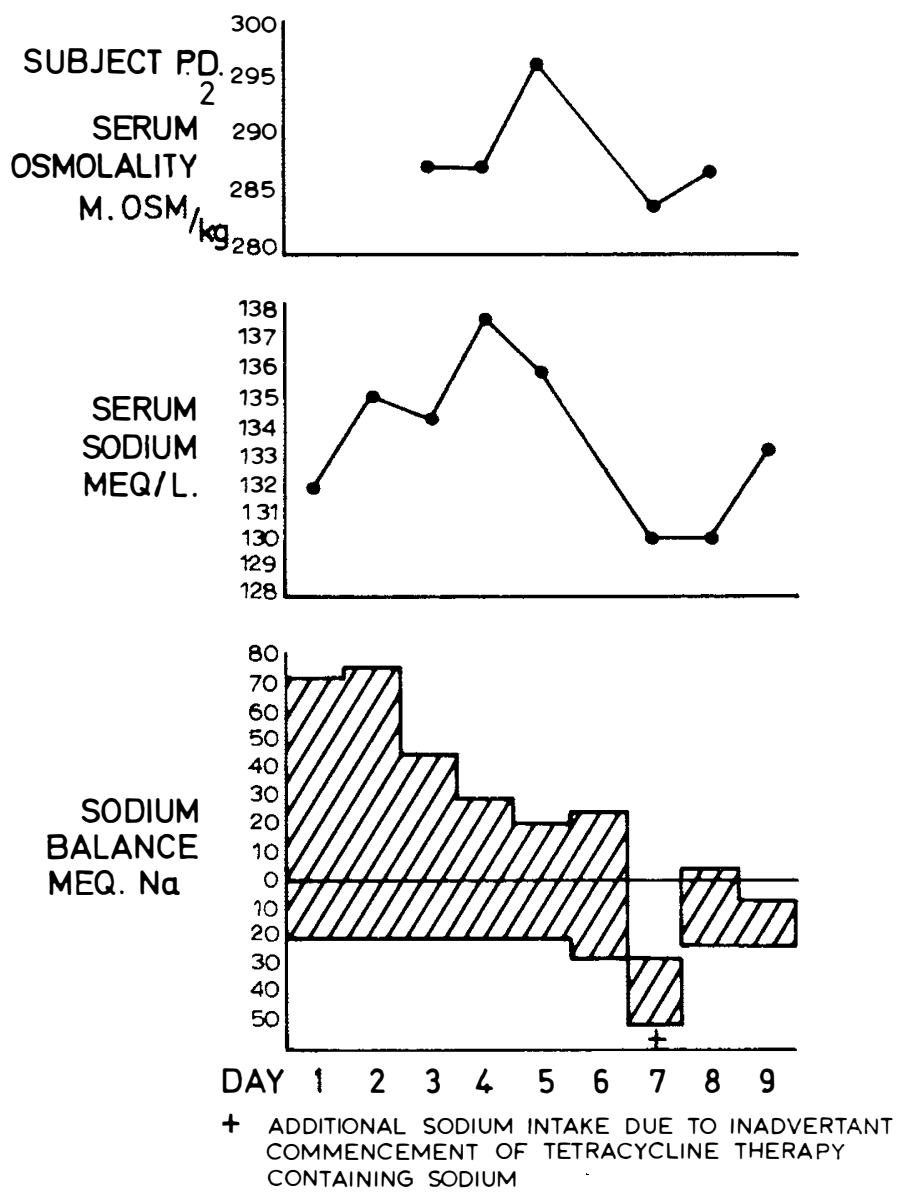

FIG. I

Results of sodium restriction (dietary intake $17-20 \mathrm{mEq}$. daily) in the second study on subject P. D. (P. D.. ). Portion of the daily urine collection on day 7 was discarded. 
normal diet is little over I mEq. per day, it was not included in the sodium balance. No patient had diarrhoea during the study. The daily urinary sodium and potassium output was determined by flame photometry on an Eel flame photometer. The quantity of sodium gained or lost during the metabolic balance study was obtained by adding the daily net balances. Figure I illustrates the pattern of results obtained in the second study in subject $\mathrm{P}$. D.

Serum and urine creatinine were measured by the method of Hare (1949).

Maximum osmolality was measured by depression of the freezing point on an Advanced Osmometer.

Total body water was measured by isotope dilution technique in subject E. O'B. before and after four weeks of unrestricted fluid intake, during which intake and output were carefully recorded. One m.c. of tritiated water was administered i.v. from a calibrated syringe in a volume of $5 \mathrm{ml}$. Five hours later a plasma sample was taken. Distillation of the plasma sample was carried out and $0 . \mathrm{I} \mathrm{ml}$. of the distillate was mixed with Io ml. of dioxan scintillator and counted in a Tri-carb liquid scintillation counter according to the method of Werbin, Chaikoff and Imade (1959).

\section{RESULTS}

Urinary volumes in general were in the range 750 to $3000 \mathrm{ml}$. (Table II) during the period of intensive study. In subject T. R. daily urinary volume was 2 to 3 litres in the initial study, but eight weeks later a further study of fluid intake and output was instituted, since urine volumes appeared to have increased. Table II (T. R.2) shows that a negative water balance of at least 8 litres was seen during eight days. Overall water balance (intake minus urinary output) was therefore clearly negative in subjects $P . D_{._{2}}$ and $T . R_{\cdot_{2}}$ only (Table II) appearing at four and ten weeks respectively following the injury and not coinciding with the period of sodium restriction and intensive study. If an allowance of $500 \mathrm{ml}$. be made for daily evaporative water loss, six of the seven subjects were in negative water balance. When total body water was measured in subject E. O'B. before and after four weeks water balance, no change was found to have occurred (see Discussion).

The mean blood pressure of the four subjects who failed to conserve sodium was maintained at satisfactory levels during the period of study varying between $75 \mathrm{~mm}$. $\mathrm{Hg}$ and $100 \mathrm{~mm}$. $\mathrm{Hg}$.

Seven external sodium balance studies were performed on six subjects. The results are shown on Table I. Figure I (subject P. D..2) is representative of the majority of the results obtained. The urinary sodium loss exceeded dietary intake for more than five days and is, therefore, abnormal by definition, but the total sodium loss over the period of study is, nevertheless, small. Thus in subject P. D.2 negative sodium balance was $2 \mathrm{I}$ and $26 \mathrm{mEq}$. daily on day 5 and day 6 of the study and balance had reverted to equilibrium by the eighth and ninth days. Similar results were seen in subjects J. P., T. R. and P. D.1. In subjects P. N., G. McL. and F. R., however, the amount and duration of urinary sodium loss was more striking (Table I). P. N. also showed a significant serial reduction in serum sodium concentration reaching $129 \mathrm{mEq}$./litre on the eighth day of sodium restriction compared with $137 \mathrm{mEq}$./litre on the first day (Table III). Mean blood pressure, however, did not alter. G. McL. showed no alteration in serum 
TABLE I

Clinical Details, Endogenous Creatinine Clearance $\left(\mathrm{C}_{\mathrm{cr}}\right)$, Maximum Urinary Osmolality, and Net Sodium Balance (i.e. dietary intake minus urinary output) in Seven Studies during Restricted Sodium Intake

(* Portion of daily urines discarded)

\begin{tabular}{|c|c|c|c|c|c|c|c|c|c|c|c|c|c|}
\hline \multirow{2}{*}{ Subject } & \multirow{2}{*}{$\begin{array}{l}\text { Level } \\
\text { of } \\
\text { spinal } \\
\text { lesion }\end{array}$} & \multirow{2}{*}{$\begin{array}{l}\text { Cor } \\
\mathrm{ml} . / \mathrm{min} .\end{array}$} & \multirow{2}{*}{$\begin{array}{c}\text { Max. } \\
\mathrm{U} \\
\text { Osm. } \\
\text { (m.Osm.) } \\
\end{array}$} & \multirow{2}{*}{$\begin{array}{c}\text { Daily } \\
\text { sodium } \\
\text { intake } \\
\text { mEq./day }\end{array}$} & \multicolumn{9}{|c|}{$\begin{array}{l}\text { Net sodium balance } \\
\text { (mEq. per day) }\end{array}$} \\
\hline & & & & & Ist & 2nd & $3^{\text {rd }}$ & $4^{\text {th }}$ & $5^{\text {th }}$ & 6 th & 7 th & 8th & 9th \\
\hline P. N. & $\begin{array}{c}\mathrm{C}_{4}-\mathrm{C}_{5} \\
\text { complete }\end{array}$ & I I 7 & I 100 & I7 & - I I & -39 & -85 & -65 & -62 & -25 & $-\mathrm{I} 6$ & - & -- \\
\hline G. McL. & $\underset{\text { incomplete }}{\mathrm{C}_{4}}$ & 102 & 827 & I7 & -25 & -10 & - II & -27 & - II & -20 & -9 & -3 & - \\
\hline F. R. & $\begin{array}{c}\mathrm{C}_{5} \\
\text { complete }\end{array}$ & -- & 939 & I7 & - II 5 & -115 & -58 & $\star-26$ & $\star-22$ & $\star+12$ & -30 & -12 & -8 \\
\hline T. R. & $\begin{array}{c}\mathrm{C}_{4} \\
\text { complete }\end{array}$ & I 28 & 905 & I7 & +2 & $-\mathrm{I} 3$ & $-2 \mathrm{I}$ & $-\mathrm{IO}$ & -7 & -2 & -8 & - & - \\
\hline P. D. 1 & $\begin{array}{c}\mathrm{C}_{7} \\
\text { complete }\end{array}$ & I39 & II 52 & I 7 & + I03 & $-I$ & -33 & -37 & -56 & -34 & $+\mathrm{I}$ & - & 一 \\
\hline P. D..$_{2}$ & $\begin{array}{c}\mathrm{C}_{7} \\
\text { complete }\end{array}$ & I 42 & 808 & I7 & -72 & -76 & -39 & -28 & $-2 \mathrm{I}$ & -24 & +27 & -3 & +9 \\
\hline J. P. & $\begin{array}{c}\mathrm{C}_{4} \\
\text { incomplete }\end{array}$ & - & 748 & I 7 & -33 & -36 & +2 & -8 & -3 & +5 & +4 & - & - \\
\hline
\end{tabular}




\section{TABLE II}

Crude Fluid Intake (unrestricted) and Output Measurements in Nine Studies, uncorrected for Extra-urinary (insensible) Water Loss. Balance (intake minus output) indicated simply as + or -

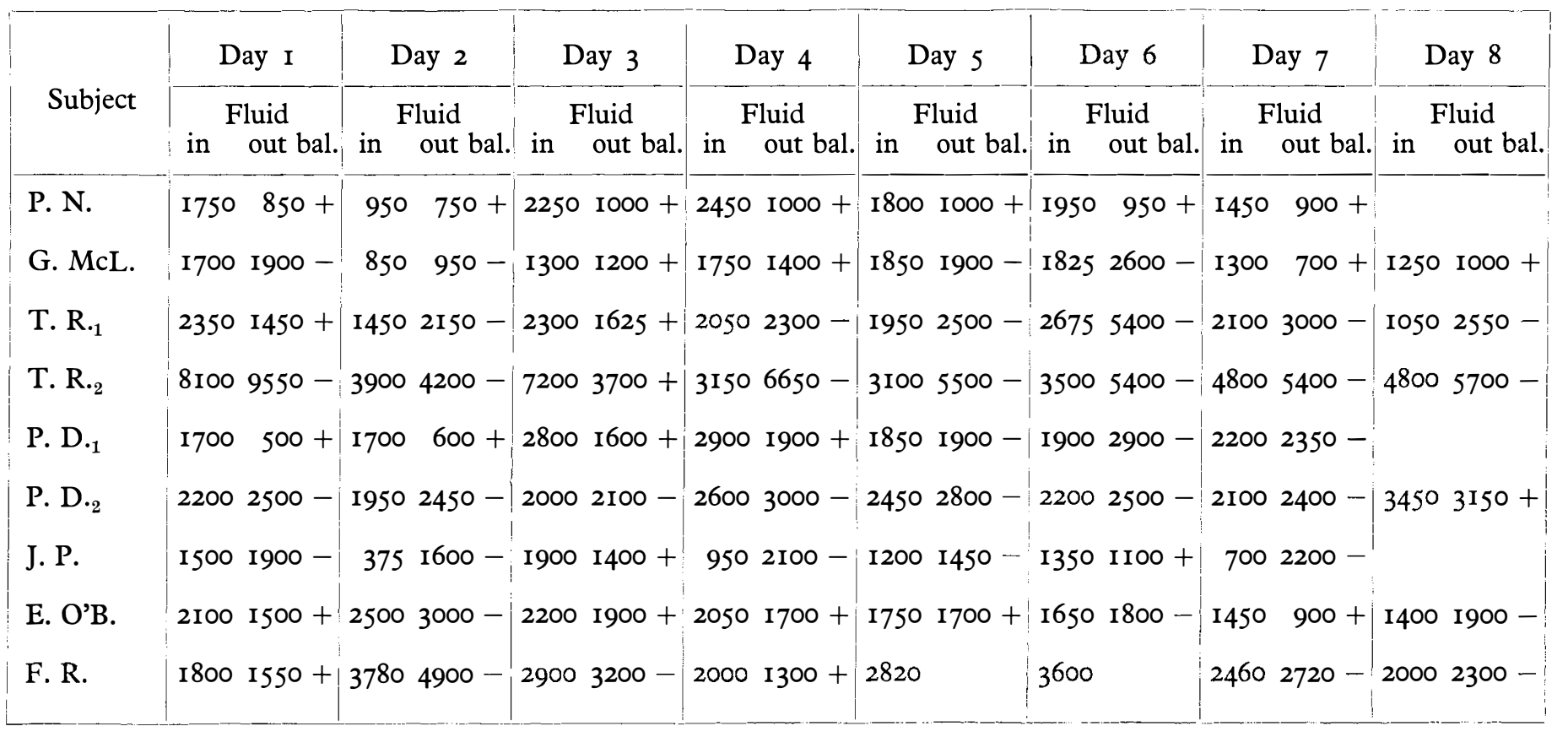


sodium concentration but mean blood pressure fell from 100 to $80 \mathrm{~mm}$. $\mathrm{Hg}$ on the sixth day of the negative sodium balance. Serum sodium in case F. R. showed an isolated drop to $127 \mathrm{mg}$./litre on the ninth day (Table III) without change in blood pressure.

\section{TABLE III}

Serial Daily Serum Sodium Measurements (mEq./litre) in Four Subjects who showed Negative Sodium Balance during Restricted Intake (see Table I)

\begin{tabular}{|l|c|c|c|c|c|c|c|c|c|}
\hline \multirow{2}{*}{ Subject } & \multicolumn{10}{|c|}{ Day } \\
\cline { 2 - 9 } & I & 2 & 3 & 4 & 5 & 6 & 7 & 8 & 9 \\
\hline P. D. & I32 & I36 & I35 & I35 & I38 & I36 & - & I30 & I33 \\
G. McL. & I30 & I30 & I29 & I3I & I33 & - & I34 & - & - \\
F. R. & I34 & - & I3I & - & I30 & - & I34 & - & I27 \\
P. N. & I37 & I36 & I35 & - & I34 & I3I & I35 & I29 & - \\
\hline
\end{tabular}

Maximum urinary osmolality varied from 748 to I I $52 \mathrm{~m}$. Osm. $/ \mathrm{kg}$. (Table I). Five of the eight tests were performed within 48 hours of the injury; the remaining three were performed two to four weeks after the injury. Normal values for urinary osmolality following I4 to I6 hours' dehydration are $955 \pm 29 \mathrm{~m}$. Osm. (Tu \& Shearn, I967).

\section{DISCUSSION}

Renal function plays an important part in the management and ultimate survival of the patient with paraplegia. It has been reported that at the present time Io to 15 per cent. of these patients die in the first ten years following spinal cord injury and that, in over half the cases, the cause of death is renal failure (Breithaupt et al., I96I). The lesions most commonly present at autopsy have been chronic pyelonephritis, renal amyloidosis and hypertension (Tribe, 1963). In the acute phase, however, death is rarely attributed to renal failure. It has been reported to occur in patients who suffer extensive soft tissue injuries and who develop as a result hypercatabolic acute renal failure (Mitchell, I965).

Thus information on any aspect of renal failure at any stage of paraplegia will be of value to those responsible for the care of these patients. Information on how the kidney reacts to paraplegia within the first few days of the spinal cord injury has been published by Doggart and Silver (1963). They found renal function adequate at this stage and the patients had a substantially normal creatinine clearance. Silver (1965) states that this period may be marked by a tendency to low urinary volumes and an elevation of blood urea. The azotaemia, however, is transient and of the prerenal type. Similarly it has been reported by Sitprija et al. that patients in early quadriplegia show normal renal function and that creatinine clearance, $\mathrm{PAH}$ clearance and maximal urinary concentration are within normal limits. The results of the present investigations support these 
findings and provide, in addition, information relating to renal handling of sodium in the period immediately following paraplegia.

In the past, several patients in the Paraplegic Unit had been noted to enter a polyuric phase of variable duration about one week following their injury. In the present study this was witnessed in the case of $T . R_{\cdot 2}$ only. In his case the urinary volumes produced were of the same magnitude as those of the patients described

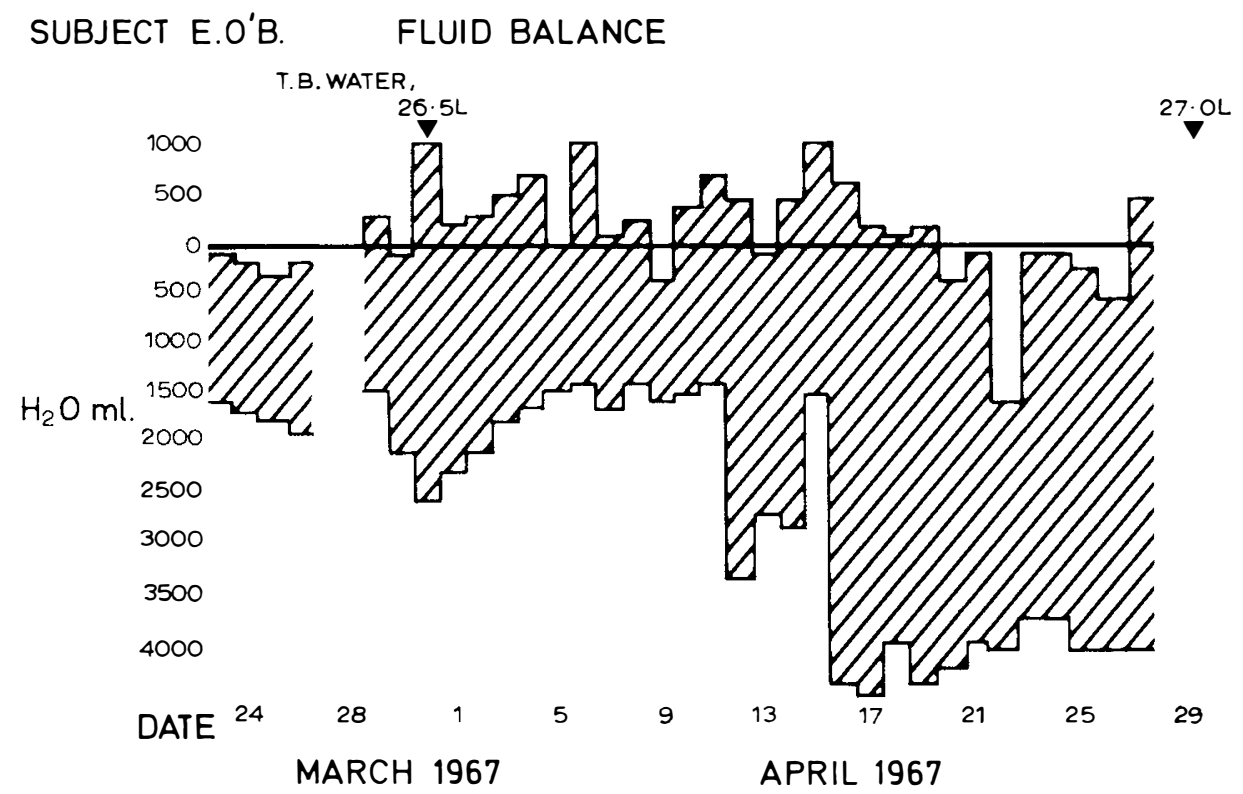

FIG 2.

Pattern of crude fluid intake and urinary output in subject E. O'B. Data are uncorrected for insensible water losses. Total body water measurements were performed as indicated.

by Sitprija et al. As it was not possible to weigh any of the patients, it was decided, following this, to measure total body water before and after such an episode in any subsequent study. This was carried out in subject E. O'B. with a four-week interval between measurements. Unfortunately, urine volumes remained relatively low in this subject, so that water 'balance' between intake and output remained in equilibrium. This was reflected in the total body measurement of 26.5 litres initially, followed by $27^{\circ} 0$ litres subsequently-an interesting confirmation of the value of the relatively crude fluid balance estimate made during the four-week period.

It can be concluded from a consideration of our own findings and those obtained by others that the advent of paraplegia is marked by no clinically important derangement of renal function. However, it has been demonstrated experimentally in the dog four days to four weeks after high spinal section that, while creatinine clearance remains normal, there is a defect in the renal response to plasma volume expansion (Pierce \& Sonnenberg, 1964). This was attributed to the loss of the spinal pathways involved in the reflex regulation of renal excretion of water and sodium. The authors quote the work of Balint and Fekete (1958) who found that water-deprived chronic spinal dogs had an impaired ability to retain sodium and 
water. These animal experiments, while of different design to our own clinical investigations, are an indication that high spinal injuries may in fact lead to some intrinsic renal abnormality evidence for which may be found only when procedures such as those described here are undertaken.

Seven sodium metabolic balance studies were performed in six patients. In three of the patients the results were abnormal and reflected a failure of sodium conservation on the part of the renal tubules. This defect, however, was not of large dimension. In the remaining patients normal or borderline normal results were obtained.

In attempting to explain the presence of such a defect in the three patients in whom it was found, several factors may be considered. In two of the patients (P. N. and F. R.) the cervical spine lesion was complete. In G. McL. it was incomplete: only one of the three (F. R.) had a uninary infection at the time of the study. It was a mild infection due to proteus vulgaris which responded to a course of oral ampicillin. Respiratory factors appear not to be involved since none of the patients showed evidence of respiratory alkalosis. The tendency for the paraplegic patient, on the contrary, is to have a somewhat elevated $\mathrm{PCO}_{3}$ (Cheshire \& Coats, I966). The most likely factor related to the results obtained in the study was the level of activity of the sodium-retaining steroid at that particular time.

It is believed by Lloyd et al. (I964) that adrenal function as a whole may be low in paraplegia due to partial secretory exhaustion. Their belief is based on the results of intramuscular ACTH challenge and their patients' water tolerance. They quote the work of Cooper and Hoen (1952), who found that in 50 per cent. of paraplegic men, the urinary I 7 -ketosteriods showed a decrease 48 hours following spinal cord injury. The patients in whom such a decrease is seen are those with lesions confined to the cervical and upper thoracic cord, according to Robinson and Munro (1958).

It is probable that this overall depression of adrenal function was present in the group of cervical patients studied by us. But it is also possible, in the case of patients with acute paraplegia at least, that there may be a more selective impairment affecting aldosterone secretion in particular. There are several reasons for entertaining such a possibility. Firstly there is the question of potassium depletion developing in acute paraplegia (Cheshire \& Coats, 1966). The potassium ion is known to be of importance in the biosynthesis of aldosterone (Bartter et al., 1964) and potassium depletion when present may reduce the efficiency of other stimuli of aldosterone (Martini \& Ganong, I966). In the particular group of patients we studied, there was little to support the presence of potassium depletion; serum potassium, for instance, was normal. The daily urinary potassium losses for the six patients was averaged at $53.8 \mathrm{mEq}$. This was slightly less than the calculated dietary intake of $\mathrm{K}$. Another reason, probably less convincing for raising this possibility, is the slight chance of severe cervical cord injuries impairing the normal function of the diencephalic control of aldosterone secretion. There are clinical, experimental and evolutionary grounds for believing that such a control centre does, in fact, exist (Farrell, 1964; Blair-West, 1964; Barrter et al., 1964; Denton, 1964). The third reason for linking acute paraplegia and aldosterone regulation and perhaps the one to which most consideration should be given, is that when the cervical region of the cord is severely damaged and autonomic pathways interrupted, the patient suffers the functional loss of his sympathetic nervous system. One of 
the roles the intact and functioning sympathetic nervous system appears to have is that of a mediator in the production of aldosterone via the renin-angiotensin system. Several recent publications have given ample proof of this role. It has been demonstrated by Taquini (I964) that stripping the kidney of its sympathetic innervation leads both to a decrease in its renin content and a fall in the granularity of juxta-glomerular cells. It has been shown by different workers that (I) the intravenous administration of a sympathomimetic agent (nor-epinephrine) stimulates the release of renin (Bugan, I966; Vander, I965), (2) that the intrarenal infusion of a sympathomimetic agent can decrease sodium excretion (Barger et al., I959), (3) that this latter process is counteracted if an adrenergic blocking agent is subsequently infused, (4) that stimulation of endogenous sympathetic activity by cold pressor tests, etc., cause the plasma renin to rise, while similar procedures in a patient with autonomic insufficiency have no effect on plasma renin (Gordon, 1967).

(5) It has also been shown that the effectiveness of the sodium-retaining steroid fludrocortisone was largely abolished by prior administration of the adrenergic blocking agent, guanethidine (Gill, I964), and (6) that the release of renin occurring with depletion of blood volume following haemorrhage is due primarily to the sympathetic vasomotor discharge and is independent of changes in arterial pressure (Bunag, I966).

Such clinical and experimental work must clearly establish for the normally functioning sympathetic nervous system a place in the involved chain of events leading to aldosterone production. However, it is not considered likely that the sympathetic nerve endings situated between renal tubular cells can act locally to facilitate sodium reabsorption by aldosterone (Pitt, 1963). The peripheral sympathetic nervous system is thus viewed in the role of a mediator in the production of aldosterone. The question must arise as to the effects, if any, of cervical cord injury on this role. When a complete lesion abolishes all sympathetic activity except perhaps some reflex activity (Silver, I965; Munro \& Robinson, 1960), it seems reasonable to suppose that aldosterone secretion will be adversely affected. Such interference would probably be present for only a limited period considering that several independent regulators of aldosterone secretion exist (Martini \& Ganong, 1966). The validity of speculation as to a relationship between cervical cord injuries, the sympathetic nervous system and sodium conservation by aldosterone could be largely confirmed or refuted by a study of either aldosterone secretion rates or plasma renin in early phase paraplegia. We think there is need for such investigations. If they were made on larger groups of patients it would be possible to draw more definite conclusions regarding the proposed relationship. The information obtained would be of value in understanding how acute paraplegia affects renal function and it might assist in some aspects the management of these patients.

\section{SUMMARY}

External sodium balance studies were performed on six subjects soon after they suffered a cervical cord injury. They demonstrated a moderate impairment on the part of the renal tubules to conserve sodium. Concurrent tests of glomerular function were normal. A possible relationship between our findings and the interruption of the sympathetic nervous system at the time of the cervical cord injury is discussed. 


\section{REFERENCES}

Balint, P. \& Fekete, A. (1958). Pfluegers. Arch. Ges. Physiol. 268, i68.

Barger, A. C., Muldowney, F. P. \& Liebowitz, M. R., (I959). Circulation, 20, 273.

Bartter, F. C., Barbour, B. H., Carr, A. A. \& Delea, C. S. (I964). Aldosterone. A symposium organized by the Council for International Organizations of Medical Sciences (Eds. E. E. Baulieu and P. Robel), p. 221. Blackwell.

Blair-West, J. (1964). Aldosterone. A symposium organized by the Council for International Organizations of Medical Sciences (Eds. E. E. Baulieu and P. Robel), p. 299. Blackwell.

Breithaupt, D. J., Jousse, A. T. \& Wynn Jones, M. (ig6i). Can. Med. Ass. F. 85, 73.

Brown, M., Pyzik, S. \& Finkle, J. R. (I959). Neurology, 9, 877.

Bunag, R. D., Page, J. H. \& McCubbin, J. W. (I966). Circ. Res. 19, 8, 5 I.

Cheshire, D. J. E. \& Coats, D. A. (1966). Paraplegia, 3, 4.

COOPER, I. S. \& HoEN, T. I. (I952). Neurology, 2, 332.

Crabbe, J., Ross, E. J. \& Thorn, G. W. (1958). F. Clin. Endocr. and Metab. I8, i 159.

Denton, D. A. (I965). Phys. Rev. 45, 2.

Doggart, J. R., Guttmann, L. \& Silver, J. R. (1966). Paraplegia, I, 3.

FARREL, G. L. (1964). Aldosterone, A symposium organized by the Council for International Organizations of Medical Sciences (Eds. E. E. Baulieu and P. Robe), p. 243. Blackwell.

Gill, J. R., Gur, V., Mason, D. T. \& Byers, S. (I964), f. Clin. Invest. 43, 2.

Gordon, R. D., KuChel, O., Liddle, G. W. \& Island, D. P. (I967). F. Clin. Invest. 46, 4. HARe, R. S. (1949). Proc. Soc. Exp. Biol. and Med. 74, I48.

Lloyd, K. E., Kaplan, L. I., Kuppermann, H. S., Grynbaum, B. B. \& Rusk, H. A. (I964). Arch. Phys. Med. E Rehab. 45, I84-192.

Martini, L. \& GANONG, W. F. (I966). Neuroendocrinology, 435.

Mitchell, G. (I965). Paraplegia, 2, 4.

Munro, A. F. \& Robinson, R. (1960). F. Physiol. 1 54, 244.

Pearce, J. W. \& Sonnenberg, H. (I964). Can. F. Physiol. and Pharmac. 43, 2 I I.

PitT, R. F. (I963). Physiology of the kidney and Body Fluids.

Robinson, R. \& MunRo, A. F. (I958). Nature, 182, 805.

Silver, J. R. T. (I965). Paraplegia, 2, 4.

Sitprija, V., Pochanugool, C., Benyajati, C. \& Suwanwela, C. (1966). Ann. Int. Med. $65,62,8$.

Taquini, A. C., Blaqvier, P. \& Taquini, A. C., Jnr. (1964). Can. Med. Ass. F. 90, 2 io.

TRIBE, C. R. (I963). Paraplegia, I, I.

Tu, W. H. \& Shearn, M. A. (1967). Ann. Int. Med. 67, IOO.

VANDER, A. J., (1965). Am. F. Physiol. 209, 659.

Werbin. H., Chaikoff, I. L. \& IMAda, M. (1959). Proc. Exper. Biol. and Med. 102, 8.

Acknowledgments. This work was made possible by a grant from the Wheelchair Association of Ireland. The authors wish to thank Dr. F. P. Muldowney, Dr. T. M. Gregg and Mr. J. D. O'Flynn for their advice and encouragement and Miss R. Freaney for the careful metabolic studies. 